\title{
DEVELOPING AN ARCHITECTURE FOR NAVAL SOVEREIGNTY OPERATIONS CENTER ${ }^{1}$
}

\author{
Todor TAGAREV and Petya IVANOVA
}

\begin{abstract}
The article summarizes the results of a comprehensive study in support of the acquisition of an advanced C4ISR system for the Navy of the Republic of Bulgaria. A small interdisciplinary team in six months has designed the essential operational views of the architecture of a complex system that provides for maritime sovereignty operations and control of sea traffic. Main challenges, such as lack of development standards, adequate procedures, and doctrinal documents, are briefly described. The approach may be used by NATO and partner countries that envision joint development and acquisition of $\mathrm{C} 2$ and surveillance systems.
\end{abstract}

Keywords: Maritime Security, Sea Surveillance, Safety of Shipping, Search and Rescue, Environmental Protection, C2, C4ISR, Enterprise Architecture, DoD Architecture Framework.

The changing risks and threats to security, the growing economic activity in the Black Sea, and the liberalization of shipping in the territorial waters and the economic zone create a qualitatively new environment for developing and employing Bulgaria's naval forces and maritime organizations. Recent trends indicate a growth of risks of accidents and catastrophes, including accidents with ships carrying hazardous load, illegal trafficking of drugs, people, arms, and dual-use technologies by sea, and maritime terrorism. ${ }^{2}$ In this environment, it is important not only to employ effectively naval forces, but to guarantee coordinated and coherent actions of all national organizations with responsibilities related to security, safety of shipping, protection of the sea borders, environmental protection, preservation of human life, sea resources, etc. The institutions of the state are expected to act quickly and in an integrated manner in order to prevent, contain, and deal with the negative consequences of variety of crises and emergencies at sea, often in coordination with non-governmental organizations and organizations from neighboring countries, partners, and allies. 
Advanced technologies - information, communications, and sensor technologies in particular - provide opportunities to meet this expectation through qualitative advances in information acquisition, situational awareness, distributed decision-making, and command and control. With this understanding, in 2002 the Ministry of Defense of Bulgaria tasked a research team from the Bulgarian Academy of Sciences to conduct a study and to propose comprehensive and feasible ${ }^{3}$ definition of requirements to an advanced C4ISR system for Bulgaria's Navy that will provide for naval sovereignty and control of sea traffic in coordination with other state institutions, local authorities, trade companies, allies, partners, and non-governmental organizations with responsibilities in these and related areas. ${ }^{4}$

This article presents a short summary of the results of the first phase of the study, ${ }^{5}$ aimed at developing a set of operational view products of the architecture of this C4ISR system.

\section{Approach}

The research team focused its efforts on the development of an architecture of the C4ISR system using known standards and best practices. For the lack of adequate Bulgarian standards in this area, the team implemented the DoD Architecture Framework, version 2.1 (First Draft), ${ }^{6}$ with references to the NATO Technical Architecture. ${ }^{7}$ The architecture was developed in an iterative procedure. A unified description was maintained in a relational database, using a commercial-off-the-shelf CASE tool.

This approach was implemented by an interdisciplinary research team with seven members, including naval officers with operational experience, experts in $\mathrm{C} 2$, sensors, sensor systems, information and communications technologies, and architecture development experts.

The broad knowledge in the team helped to overcome some significant gaps. For example, a number of documents, which would be readily available to a developer of an architecture, e.g., in the U.S., were not available at the time the study was done. Thus, one of the useful by-products of the study was the structured description of naval task lists. ${ }^{8}$ The remaining part of this article lists the topics, studied prior to architecture development, and briefly presents operational view products of the architectural description.

\section{Groundwork}

In order to fill in gaps in legislature, planning documents, and doctrine, the research team conducted preliminary analysis on several issues. The main findings and conjectures are listed bellow. 


\section{Scope of the System}

The system under study consists of two major components: (1) the Coastal System for Control of Sea Traffic ${ }^{9}$ and (2) the Naval Sovereignty Operations Center (NSOC). The first includes the set of information sources based on shore, posts for acquisition and processing of information, $\mathrm{C} 2$ centers and the supporting communications and information infrastructure.

The NSOC is the main component of the system for maritime sovereignty with the following functions:

(1) Collection of data and information from sensors based on coast, sea surface, subsurface, air and space, as well as reports from troops acting in the area of responsibility;

(2) Processing, visualization, transmission and storage of information on the situation in the national sea spaces, on subordinated and interacting forces and assets;

(3) Situation assessment;

(4) Decision-making, planning, and re-planning;

(5) Control of subordinated forces and assets;

(6) Coordination with other forces and assets of the Bulgarian Armed Forces, other state institutions, local authorities, trade companies, allies and partners, non-governmental non-for-profit organizations;

(7) Simulation of crisis management activities.

As a result, the team limited the study to the part of the C4ISR system of Bulgaria's Navy, based on the coast, and its interfaces to forces and assets of the Navy at sea and in the air, forces and assets of other services and defense agencies, of NATO, NATO member states and partners, other state agencies, local authorities, trade companies and non-profit organizations, as well as to other information sources.

From a systems point of view, it consists of three main (sub-) systems:

(1) Sensor system - radar, radio, optical-electronic (including infrared), hydroacoustic, meteorological, IFF, etc.;

(2) Integrated communications and information system (or backbone); and

(3) Decision support system that supports situational awareness, decision making, planning, control, etc.

\section{Operational Issues}

The team analyzed the concept of 'control' and 'sovereignty' of the sea spaces, their scope, respective players, objectives and tasks, as well as the definitions of their spa- 


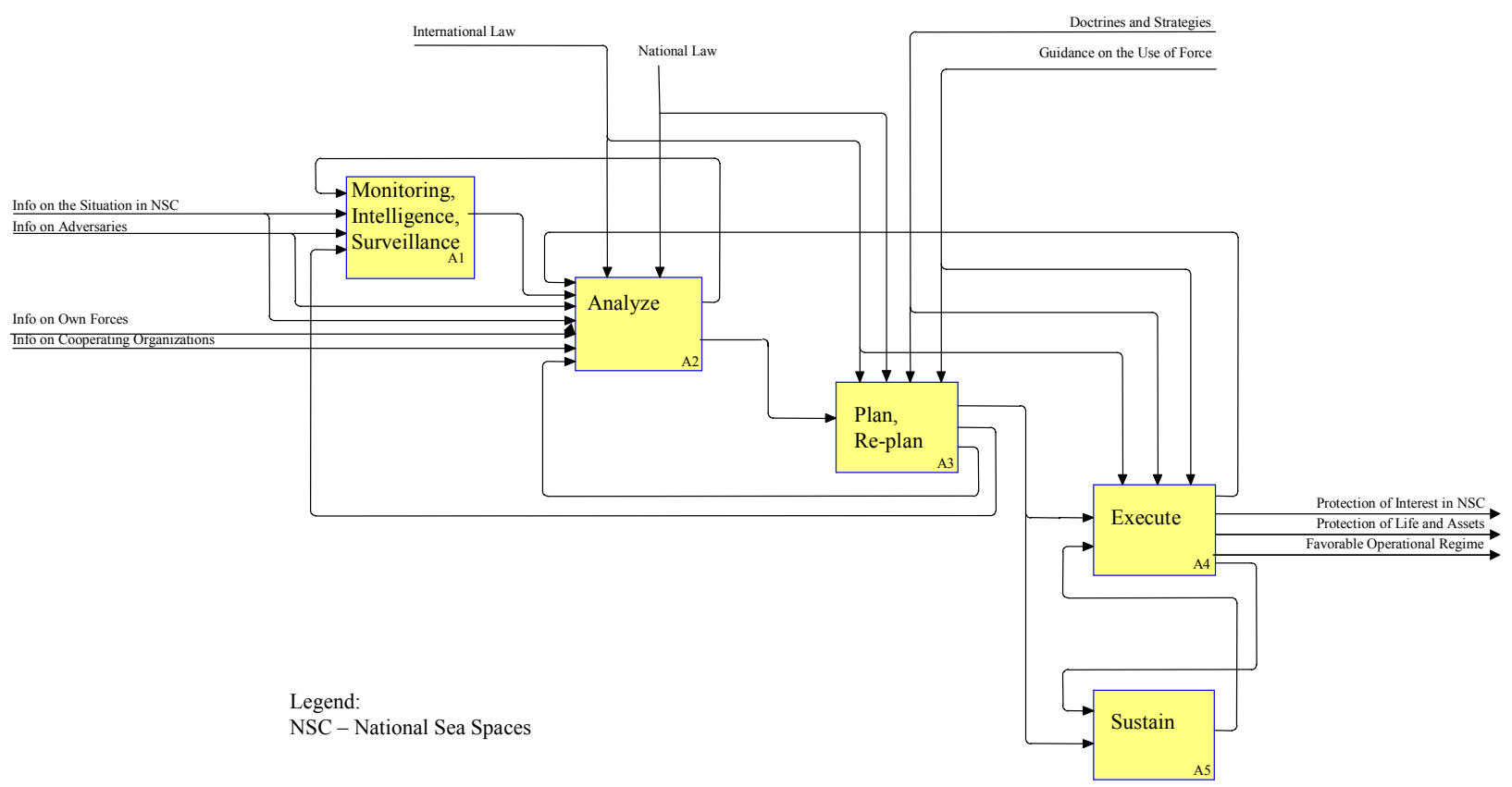

Figure 1: Main Command, Control, an Execution Cycle. 
tial organization. It looked at current operational environment. Analyzing statistics and tendencies of threats, risks, and illegal acts, the team defined critical services.

Then, the team analyzed some doctrinal aspects and the characteristics of the operations for control of the national sea spaces and control of shipping. One result was the choice of the MAPES (Monitor, Assess, Plan, Execute, Sustain) cycle ${ }^{10}$ for presentation of the main $\mathrm{C} 2$ and operational activities. This choice has an important impact on the structuring and the presentation of all operational activities (Figure 1). The team also developed structured lists of generic tasks Bulgaria's Navy (or allied and partner navies) perform on three levels - strategic, operational, and tactical. ${ }^{11}$

\section{Organizational Models}

Finally, in the preparatory phase the team compared four organizational models for control of the national sea spaces: multifunctional state agency (para-military organization of the type of the US Coast Guard); total state control; integrating supraagency (the 'French model'); network model. The team concluded that the network model is the most realistic model for development of the national system for control of the sea spaces. Its realization, however, would be hindered by lack of experience and the specific organizational culture of Bulgaria's state institutions, shaped in the years of transition to democracy and market economy.

\section{Operational Views}

The operational architecture view is a description of the tasks and activities, operational elements, and information flows required to accomplish or support a military or multi-agency operation. It defines the types of information exchanged, the frequency of exchange, which tasks and activities are supported by the information exchanges, and the nature of information exchanges in detail sufficient to ascertain specific interoperability requirements.

In the first phase of the study the team developed the following Operational Views (OVs) of the architecture:

- OV-1 High-Level Operational Concept Graphic;

- OV-5 Activity Model;

- OV-2 Operational Node Connectivity Description;

- OV-3 Operational Information Exchange Matrix.

In defining the activity model, and drawing on the structured tasks lists, the team created a hierarchy of the main activities and designed three detailed representations:

- Planning at NSOC and other C2 centers and headquarters (the MAPES cycle in Figure 1 provides an aggregated view); 


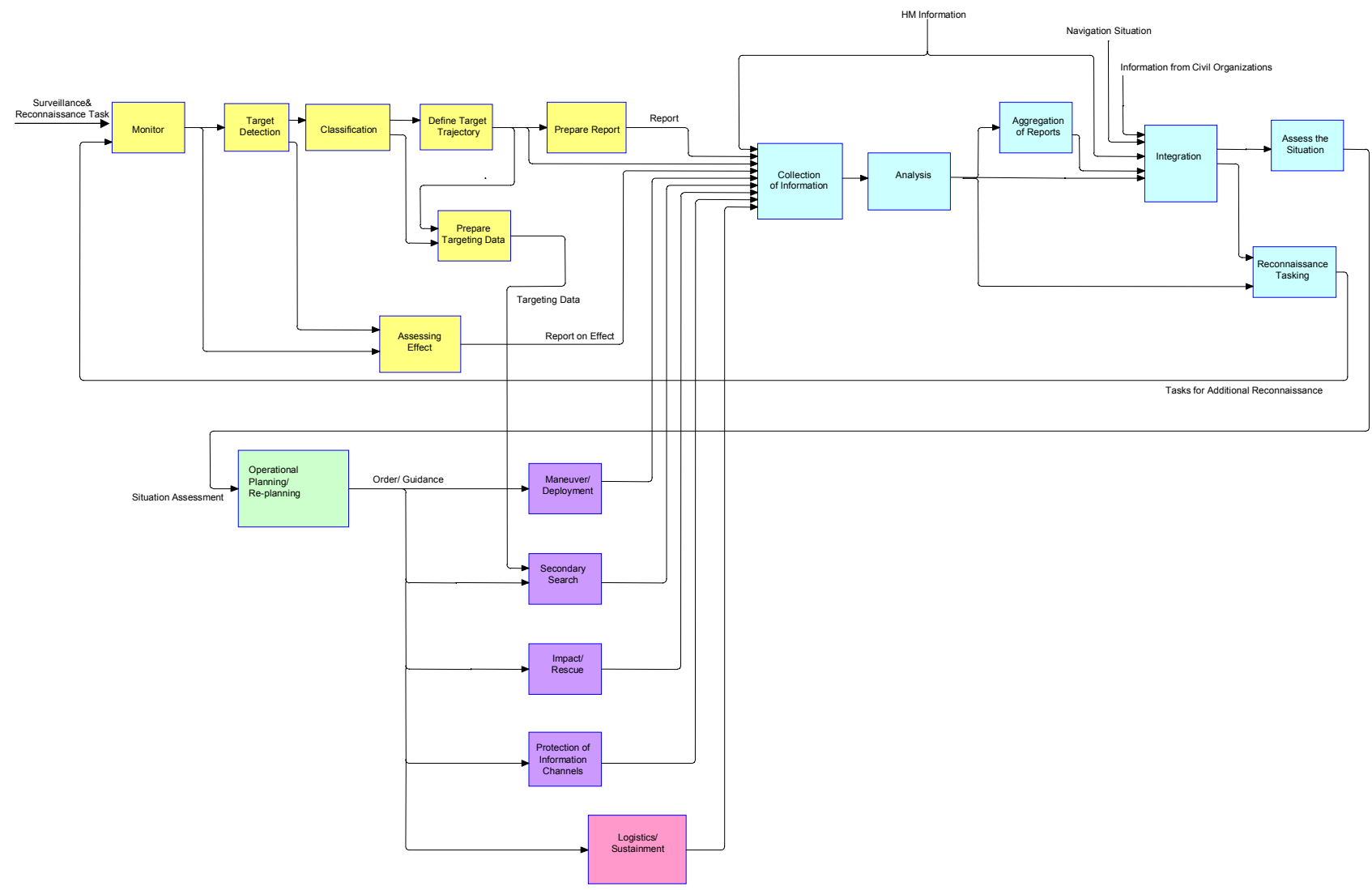

Figure 2: Model of Activities in Crisis Operation. 
- Model of activities in combat operation;

- Model of activities in other crisis operations, e.g., search and rescue at sea (presented in Figure 2).

In studying the connectivity of the system and information exchange requirements, the team identified several dozens national normative documents that define roles and missions of over 30 state agencies and, occasionally, modes of their interaction with other agencies. In addition, the team studied accessible standards and other documents of NATO (EXTACs), the International Maritime Organization (IMO), the European Union, organizations of the Black Sea countries, i.e., BlackSeaFor, ${ }^{12}$ district authorities and municipalities, non-governmental organizations, i.e., the Organization of the Red Cross, shipping companies, etc.

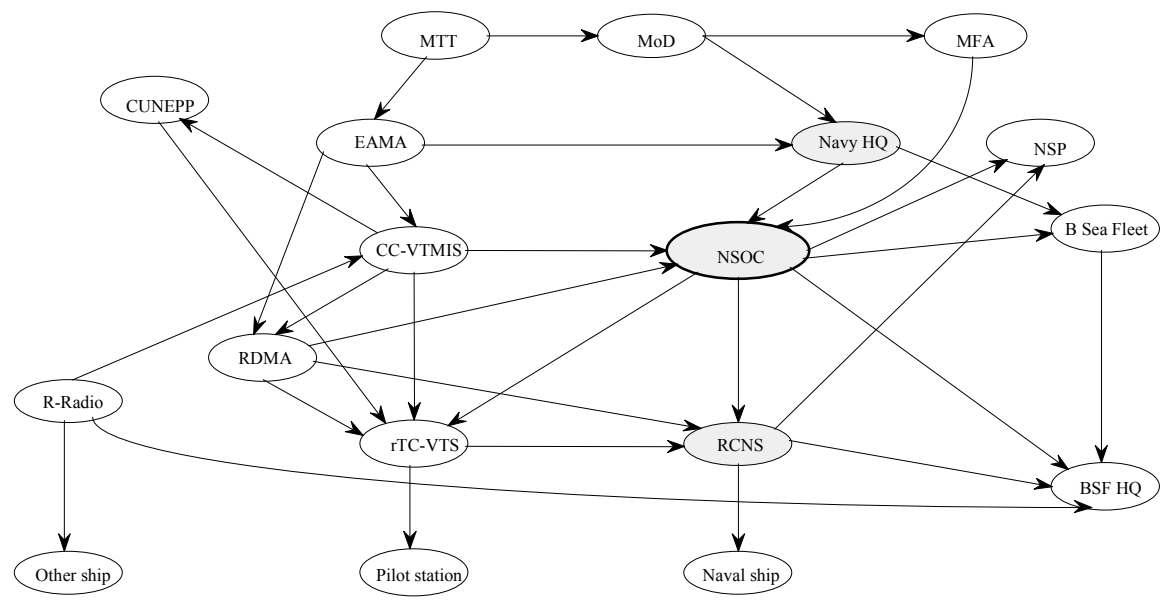

Legend:

CUNEPP - Committee on the Use of the Nuclear Energy for Peaceful Purposes

RDMA - Regional Directorate of Maritime Administration

EAMA - Executive Agency on Maritime Administration

CC-VTMIS - Coordination Center of the Vessel Traffic Management Information System BSF - Bulgarian Sea Fleet (company) rTC-VTS - Regional Territorial Center of the Vessel Traffic System RCNS - Regional Center for Naval Sovereignty NSP - National Service for Protection

Figure 3: Node Connectivity in Providing Safety of Shipping. 
Four main scenarios were used to describe connectivity among logical nodes of the architecture in operations involving various non-military actors:

- Maritime safety (the respective portion of OV-2 is presented in Figure 3. The Coordination Center of the Vessel Traffic Management Information System /CC-VTMIS/ is the central node aside from the NSOC);

- Law Enforcement;

- Environmental Safety;

- (non-combat) Search and Rescue.

Other scenarios were used to encompass all requisite connectivity in combat operations.

The Information Exchange Matrix (OV-3) lists operational information elements exchanged between sending node/activity and receiving node/activity. Each information exchange was described according to frequency, volume, timeliness, criticality, security classification, perishability, and checking requirements.

Finally, the team proposed a structure of the Naval Sovereignty Operations Center and analyzed the opportunities to integrate two systems under development- the coastal radar surveillance system of the Border Police and the Vessel Traffic System of the Maritime Administration — with the C4ISR system of the Navy.

\section{Conclusion}

The approach used in the presented study leads to a complete and coherent description of the requirements to C4ISR systems. Importantly, while allowing to account for trends in technology development, it provides clear definition of requirements without prescribing specific technical products, hence the provision for fair competition among bidders. Once a contract is signed, the architectural description is used to monitor how requirements are implemented. Not the least, the use of architectural descriptions in compatible architecture frameworks provides for interoperability both with other players and with legacy systems and serves as a common 'language' among allies.

The authors want to believe that Bulgarian authorities, or at least the Ministry of Defense, will not delay further the introduction of respective standards and procedures to guide C4ISR system acquisition. 


\section{Notes:}

1 This paper presents a summary of the authors' presentation to the $2^{\text {nd }}$ International Conference "The Bulgarian Navy - New Missions, Roles and Capabilities," organized by the AFCEA-Varna Chapter, 29 - 30 September 2003, Riviera Resort, Varna, Bulgaria.

${ }^{2}$ On the maritime dimension of terrorism the reader may refer to Joshua Sinai, "Future Trends in Worldwide Maritime Terrorism," Connections: The Quarterly Journal 3, no. 1 (March 2004): 49-66; and Mark E. Kosnik, "The Military Response to Terrorism," Naval War College Review 13, no. 2 (Spring 2000): 13-39.

3 One that can be built within a realistic resource framework.

4 Emil Lyutzkanov (Rear Admiral, BU N), "Bulgaria in NATO: New Roles and Capabilities of the Navy," Information \& Security: An International Journal 13 (2004): 9-24, $<\mathrm{http}: / / \mathrm{cms}$.isn.ch/public/docs/doc_10444_259_en.pdf> (15 Apr 2005).

5 The initial plan was to conduct a two-phase study for approximately 18 months. The Ministry of Defense did not turn to the Bulgarian Academy of Sciences for the second phase, that had to result in definition of the system requirements, a set of technical standards and development plan. To the best of the authors' knowledge, there has been no publicly open procedure to contract either the study, or the design and the development of this C4ISR system.

${ }^{6}$ Currently replaced by DoD Architecture Framework, version 1 (Washington, DC: DoD Architecture Framework Working Group, February 2004).

${ }^{7}$ NATO C3 Technical Architecture, ADatP-34, Version 3.0, volumes I, II, III, IV and V (NATO ISSC Open Systems Working Group, 15 December 2001).

8 Boyan Mednikarov and Peter Dereliev, "Structured Description of Naval Tasks," Information \& Security: An International Journal 13 (2004): 25-34, <http://cms.isn.ch/ public/docs/doc_10445_259_en.pdf> (15 Apr 2005).

9 Sometimes referred to as 'Ekran' (Shield).

${ }^{10}$ This model is used by the US Navy, Marine Corps, and Coast Guard.

${ }^{11}$ Mednikarov and Dereliev, "Structured Description."

${ }^{12}$ See BlackSeaFor Agreement, <www.blackseafor.org> (21 October 2004); Peter Petrov (Vice Admiral, BU N), "Towards Creation of a Unified Information System of the Navies of the Black Sea Countries," Information \& Security: An International Journal 6 (2001): 94101, <http://cms.isn.ch/public/docs/doc_775_290_en.pdf > (16 April 2005). 
TODOR TAGAREV is Associate Professor and Chair of the Defense and Force Management Department of "G.S. Rakovski" Defense and Staff College, Sofia, Bulgaria. He was the first Director of the Defense Planning Directorate since its establishment in early 1999. From May until late 2001, he served as Director for Armaments Policy in the Bulgarian Ministry of Defense and National Armaments Director. Among other duties, he coordinated all defense modernization and R\&D programs in support of defense reform and NATO integration. He graduated from the Bulgarian Air Force Academy in 1982 and received a $\mathrm{PhD}$ degree in systems and control from Zhukovsky Air Force Engineering Academy, Moscow, in 1989. Dr. Tagarev is a 1994 Distinguished Graduate of the US Air Command and Staff College at Maxwell Air Force Base, Ala., and a 1994 Distinguished Young AFCEAn. Dr. Tagarev is Managing Editor of Information \& Security: An International Journal. E-mail: infosec@procon.bg.

PETYA IVANOVA is currently Senior Researcher at Information Services plc. Her main responsibilities are design and development of Business Intelligence solutions for the Bulgarian Customs and the Ministry of Finance. After a nine-year academic career, she joined Honeywell Technology Center Europe, in 1999, as Research Engineer working on various data mining projects. From December 2000 until January 2002 she was Senior Scientists at BiosGroup, Sofia Branch, dealing with the application of complexity science to business problems. She has more than forty publications in the areas of image processing, time series prediction, nonlinear dynamics, nolinear optimization, IS architecture and development, soft computing technologies, and decision support.E-mail: entarch@gmail.com. 